\title{
Caracterización de la carne de cuy empacado al vacío. Un estudio para su exportación
}

\author{
Characterization of the vacuum packed guinea meat. A study for export \\ Caracterização da carne de cobaia embalada a vácuo. Um estudo para \\ exportação
}

\author{
Elsa Estrada \\ elyestrada7@gmail.com \\ ORCID 0000-0002-3503-4003
}

\author{
Grace Alexandra Velastegui Bosquez \\ gracealexandravelastegui@gmail.com \\ ORCID 0000-0001-6391-9733
}

Universidad del Zulia, Núcleo Costa Oriental del Lago. Venezuela

Artículo recibido enero 2021 | Arbitrado en febrero 2021 | Publicado en mayo 2021

RESUMEN

Los cambios de hábitos en el consumo de alimentos, insinúan productos de fácil preparación y oportuna adquisición en supermercados, es así como la carne de cuy, por su alto valor nutritivo, es clave para la seguridad alimentaria. Así pues, el objetivo de la investigación fue caracterizar la carne de cuy empacado al vacío para su exportación. La metodología se concretó en el análisis de la cadena de comercialización con especial atención en los actores más importantes. La carne se caracterizó utilizando análisis de varianza para las diferencias y comparación de medias, según Duncan $(\mathrm{p}<0.05)$, desde el punto de vista físico-químico, microbiológico $\mathrm{y}$ sensorial. Para incrementar las exportaciones, es de vital importancia aumentar la producción para ello es indispensable que los pequeños $\mathrm{y}$ grandes criaderos se asocien $y$ trabajen en forma conjunta y por un mismo objetivo.

Palabras clave: Carne de cuy; consumo de alimentos; empacado al vacío; exportación, valor nutritivo

ABSTRACT

RESUMO

Changes in food consumption habits suggest products that are easy to prepare and timely purchase in supermarkets. This is how guinea pig meat, due to its high nutritional value, is key to food safety. Thus, the objective of the investigation was to characterize the meat of guinea pig vacuum packed for export. The methodology was specified in the analysis of the commercialization chain with special attention to the most important actors. The meat was characterized using analysis of variance for differences and comparison of means, according to Duncan ( $p<0.05)$, from the physicalchemical, microbiological and sensory point of view. To increase exports, it is vitally important to increase production. For this, it is essential that small and large hatcheries associate and work together and for the same objective.

Key words: Guinea pig meat; food consumption; vacuum packed; export; nutritional value
Mudanças nos hábitos de consumo alimentar sugerem produtos de fácil preparo e compra na hora certa no supermercado, por isso a carne de cobaia, por seu alto valor nutritivo, é fundamental para a segurança alimentar. Assim, o objetivo da investigação foi caracterizar a carne de porquinho-da-índia embalada a vácuo para exportação. A metodologia foi especificada na análise da cadeia de comercialização com atenção especial aos atores mais importantes. A carne foi caracterizada por meio de análise de variância para as diferenças e comparação de médias, segundo Duncan $(\mathrm{p}<0,05)$, do ponto de vista físico-químico, microbiológico e sensorial. Para aumentar as exportações é de vital importância o aumento da produção, para isso é imprescindível que pequenos e grandes incubatórios se associem e trabalhem juntos e para o mesmo objetivo.

Palavras-chave: Carne de porco-daíndia; consumo de comida; embalado a vácuo; exportação, valor nutricional 


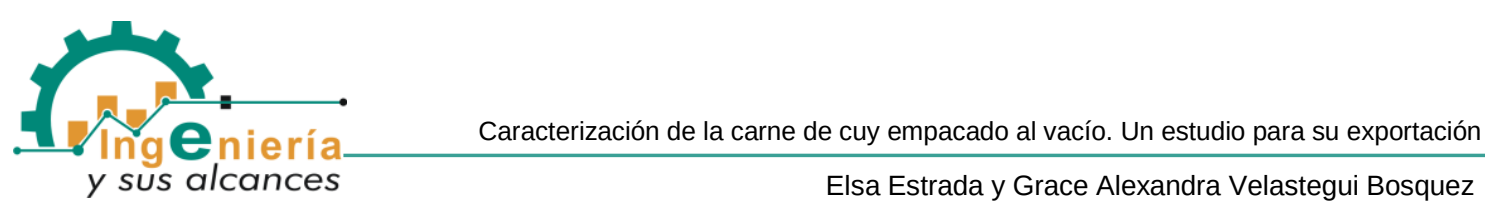

INTRODUCCIÓN

El cuy es un mamífero roedor originario de la Cordillera de los Andes de Colombia, Ecuador, Perú y Bolivia, donde ha sido utilizado, principalmente, como fuente de alimento, además que proporciona importantes ingresos económicos a las familias rurales por la venta de sus excedentes en el mercado local, además que ha tomado mucha fuerza en el mercado gastronómico internacional en forma de plato típico exótico, entre otros usos.

Como la alimentación de esta especie se basa en insumos que no compiten con la alimentación humana (Meza, et al., 2014), en los últimos años, la crianza de esta especie y el consumo de su carne se ha incrementado (Robles et al., 2014), favorecidos por la calidad nutricional de la carne, las propiedades organolépticas y la versatilidad de consumo (Apráez et al., 2011), y debido a la disminución de insumos, se hace necesario evaluar alimentos promisorios como fuente de alimentación.

Entre otros indicadores, las características productivas del cuy y su carne, se pueden medir a través de la ganancia de peso corporal, el rendimiento de la carcasa, el pH, la capacidad de retención de agua (CRA) y el color (Sánchez, Hernández y Durán, 2010). El pH afecta la calidad y la terneza de la carne (Bidner et al., 2004), una CRA baja conlleva a la pérdida de agua de la carne que afecta la jugosidad y la palatabilidad (Zhang et al. 2005), y el color de la carne como atributo muy valorado por los consumidores, podría considerarse un criterio de preferencia.

Por tanto, existe el reto de convertir la carne de cuy en la alternativa de proteínas a bajo costo y un elemento del desarrollo del sector agropecuario. De manera que, las exportaciones de carne de cuy, que empezaron en los años 90's, han sido impulsadas desde el año 2000, por intervención de los exportadores, presentando una caída en el 2009, una recuperación posterior a dicho año, así como una nueva caída en el 2013; no obstante, para el año 2019 Ecuador reportó un promedio de 21 millones de cuyes que, debido a su constante reproducción, producen 47 millones de cuyes anuales que son destinados a la venta y consumo familiar. Así lo informó el Ministerio de Agricultura, Ganadería, Acuacultura y Pesca (MAGAP, 2019).

En este contexto, surge la presente investigación, cuyo objetivo se centró en caracterizar la carne de cuy empacado al vacío para su exportación. Para tal fin, se realizó un diagnóstico del alcance, condiciones, principales canales, actores, mercados que componen la cadena de exportación del cuy al territorio estadounidense, tanto de producción como de mercadeo, que se consideran de influencia para el producto contemplados dentro de la empresa ECUANUTRIONIMEX S.A.

Dicha empresa, establece una actividad de producción de crianza tecnificada de cuyes, bajo un sistema de alimentación de alfalfa y balanceados, ambos ecológicos; teniendo como ventaja que además de ser un animal herbívoro, su ciclo reproductivo es corto, de fácil adaptación a diferentes ecosistemas y su alimentación versátil que utiliza insumos no competitivos como la alimentación de otros monogástricos. 


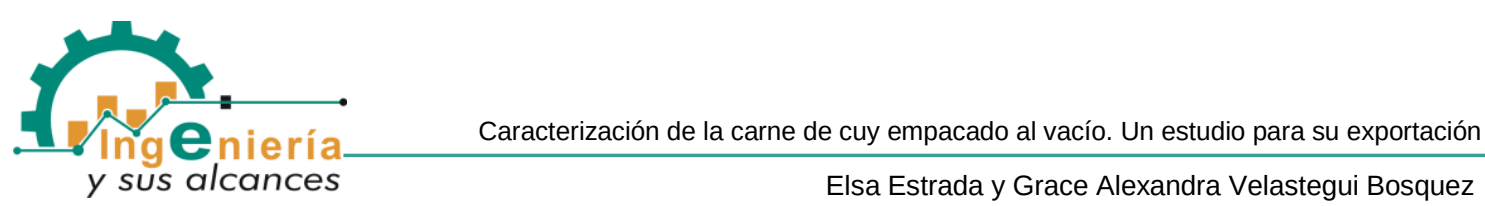

\section{Aspectos teóricos}

En el Ecuador existen cuyes sin una definición característica propia, por lo que es difícil establecer razas definidas de cuyes, en razón de que los animales existentes actualmente provienen de las líneas criollas, que por tratarse de animales propios del continente y que fueron domesticados en la época incaica, se habla entonces de una especie doméstica nativa (Manual Agropecuario, 2002).

Hoy en día aún persiste la crianza de cuyes criollos, a nivel de indígenas y campesinos en las zonas periféricas de ciudades hasta una altura de 3500 metros sobre el nivel del mar. Mientras que a nivel de productores que están más cercanos a criaderos tecnificados, manejan cuyes de mejor calidad principalmente cruzados con líneas puras procedentes del Perú. (Cruz, 2008).

La raza criolla es un animal rústico que no necesita instalaciones sofisticadas, pues por sus condiciones naturales es apto resistir las inclemencias del tiempo. Además, por ser básicamente herbívoro, exige poco alimento procesado o grano. $\mathrm{Su}$ cuerpo es alargado con poco desarrollo muscular y su crecimiento es menor al de las líneas mejoradas; La hembra tiene entre dos y tres crías por parto con un peso promedio al nacimiento por individuo de $100 \mathrm{~g}$, al destete pueden alcanzar 180 y 350 $\mathrm{g} \mathrm{y}$ a los tres meses llegar a pesos superiores a los 700 g (Manual Agropecuario, 2002).

En cuanto al color, tiene diferentes tonalidades donde sobresalen el negro, café o chinchilla, gris, bayos, rojos, blancos y mezclas entre dos de estos colores. Los animales de color negro, café y gris tienen poca aceptación en el mercado, en razón que el color del pelo pigmenta también la piel, lo que crea un mal aspecto y poca aceptación en el mercado. En cuanto al pelaje, existen largo y arremolinado, y con respecto a su conformación, suelen ser cabeza alargada, cuello largo (Cruz, 2008).

La raza de cuyes mejorados tiene una conformación enmarcada dentro de un paralelepípedo, clásico en las razas productoras de carne. La tendencia es producir animales que tengan una buena longitud, profundidad y ancho. Esto expresa el mayor grado de desarrollo muscular, fijado en una buena base ósea. Son de temperamento tranquilo, responden eficientemente a un buen manejo y tienen buena conversión alimenticia (Chauca, 2016).

La procedencia de los animales genéticamente mejorados ha sido generalmente de Perú, en donde durante décadas han emprendido la investigación con fines de lograr genotipos de mejor conversión alimenticia, de colores y pelaje aceptados en el mercado. Fruto de este esfuerzo se lograron determinar algunos tipos como el Perú, Andina, Inti (Figura 1); de los cuales, el cuy de la línea Perú principalmente, ha sido introducido y muy difundido en Ecuador, razón por la cual viene la denominación de cuy peruano mejorado (Cruz, 2008). 


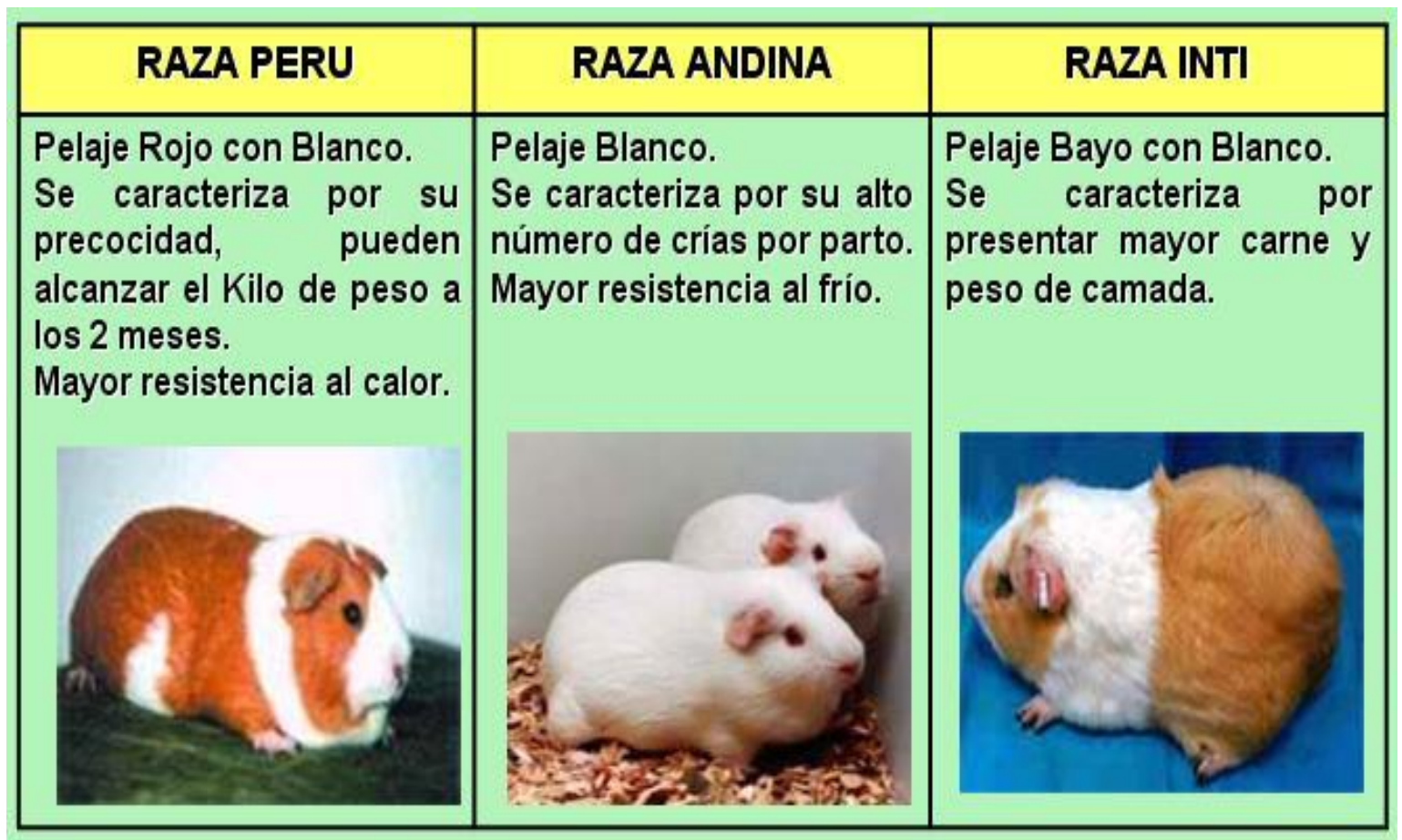

Figura 1. Tipos de cuyes.

Respecto a la Línea Perú, esta es seleccionada por su precocidad; ya que a las nueve semanas alcanza su peso de comercialización; y puede presentar un índice de conversión alimentaria de 3,81 si los animales son alimentados en condiciones óptimas; su prolificidad promedio es de 2,8 crías por parto. Son de pelaje de tipo 1, de color alazán (rojo) puro o combinado con blanco. Estos animales se caracterizan por tener una mejor conversión alimenticia, son prolíficos, mansos, cabeza redondeada, cuello corto y pelo liso; alcanza pesos entre 1000 a $1400 \mathrm{~g}$ a partir de los 90 días de edad; los colores característicos son: bayos (amarillos), blancos, rojos y tonalidades intermedias debido al cruce (Cruz et al. 2008).

En cuanto a la línea Andina se selecciona por el tamaño de la camada, ya que permite obtener 3,2 crías por parto y un mayor número de partos en un año, su color es blanco. Para la línea Inti se tienen en cuenta las dos características anteriores, la precocidad y la prolificidad y se genera un animal intermedio entre el peruano y el andino; su color es bayo con blanco. (Manual Agropecuario, 2002).

Ahora bien, indistintamente del tipo de cuyes, se identifican tres niveles de producción, caracterizados por la función que esta cumple dentro del contexto de la unidad productiva. Los sistemas de crianza identificados son el familiar, el familiar comercial y el comercial. En el área rural el desarrollo de la crianza ha implicado el pase de los productores de cuyes a través de los tres sistemas. (Zaldívar et al. 2001).

La crianza familiar, es el sistema de cría cuyo objetivo es producir carne para complementar la dieta familiar (autoconsumo). El manejo lo realiza la familia, especialmente las mujeres y los niños; utiliza instalaciones muy rústicas y 
los sistemas de alimentación están relacionados con muchos de los productos y subproductos obtenidos en la zona. (Manual Agropecuario, 2002).

Mientras que, el sistema de crianza familiar - comercial corresponde a un nivel de productores con mayor proyección de mercado, poseen un manejo más tecnificado tanto en construcciones, mejor material genético, alimenticio y sanitario, el número de crías en promedio es de 9 gazapos hembra/año, la alimentación se basa en forraje y poco concentrado. (Manual Agropecuario, 2002).

Por su parte, la crianza comercial (tecnificado), es un sistema poco difundida y más circunscrita a valles cercanos a áreas urbanas; se trata de la actividad principal de una empresa, donde se trabaja con eficiencia y se utiliza alta tecnología, la tendencia es a utilizar cuyes de líneas selectas, precoces, prolíficas y eficientes convertidores de alimento. (Zaldívar, 2001).

\section{MATERIALES Y MÉTODOS}

Una vez seleccionados los cuyes por la empresa ECUANUTRIONIMEX S.A, cuyo sistema de crianza estuvo basado de manera técnico, con alimentación a base de alfalfa y desechos de cosecha, complementada con concentrado. Se aplicó la técnica descriptiva para evaluar sensorialmente la carne cruda de las líneas de cuyes seleccionadas, considerando las características organolépticas, aspecto $\mathrm{y}$ olor, como las más importantes, teniendo en cuenta la naturaleza del mencionado ingrediente y del proceso tecnológico por seguir.

Se utilizó un total de 32 cuyes machos de la línea Ecuador (tipo I) con edad promedio de 3 meses y peso inicial de $761 \pm$ 134 g. Los animales se distribuyeron aleatoriamente en 4 grupos de 8 cuyes cada uno. Durante el tiempo de investigación, los animales permanecieron en jaulas metálicas $(0,65 \times 0,70 \times 0,25 \mathrm{~m})$ (Figura 2) que tenían comederos tipo canaleta $\mathrm{y}$ bebederos automáticos. Antes del experimento, estos animales fueron sometidos a un período de adaptación durante 15 días. Cada animal fue identificado a través de un arete con su respectiva enumeración.

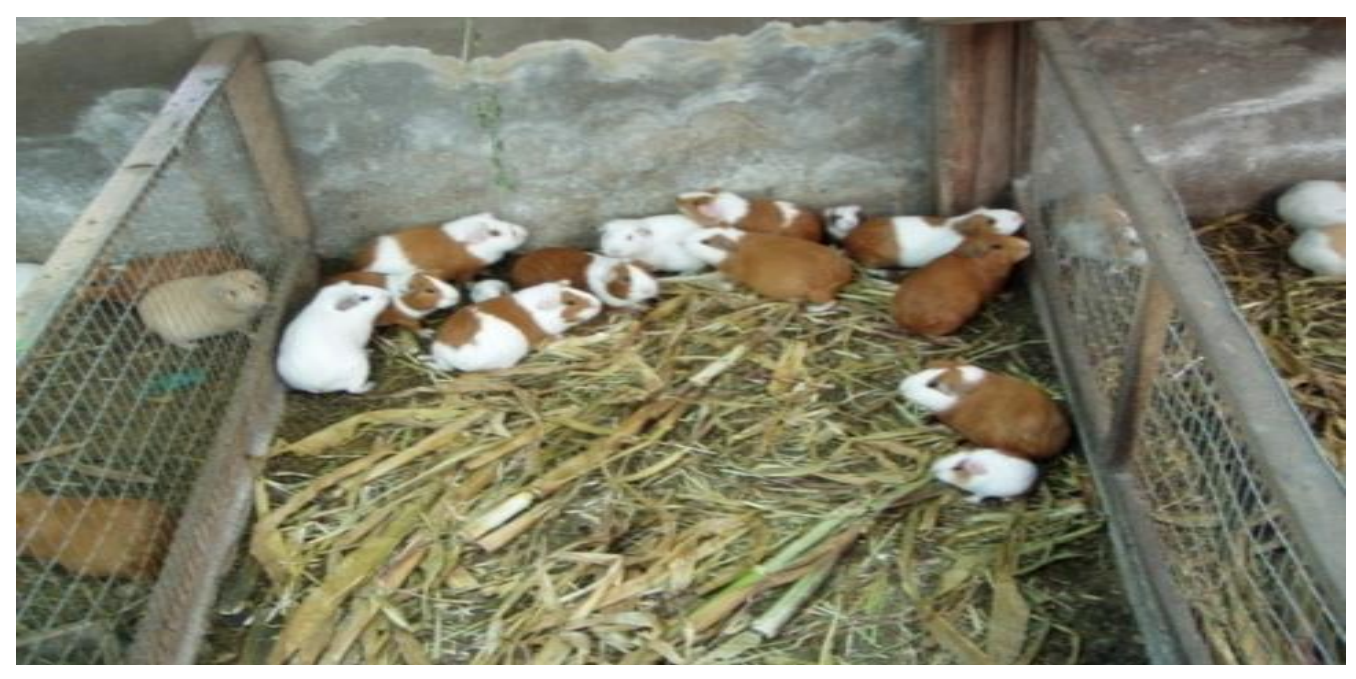

Figura 2. Fotografía jaula metálica. 
Las pruebas se realizaron en una sala de catación con las condiciones referidas por la NC ISO 1035 (2021) y con la participación de 5 catadores adiestrados en este tipo de producto. De igual manera, la carne se caracterizó utilizando un análisis de varianza para las diferencias y comparación de medias, según Duncan $(\mathrm{p}<$ $0,05)$, desde el punto de vista físicoquímico, microbiológico y sensorial.

Se estimó el incremento de peso corporal vivo por día para lo cual los animales se pesaron cada 7 días, y el rendimiento de la carcasa al final del estudio con previa remoción de pelaje y eviscerado (Tandzong, et.al., 2015). Al respecto, el sacrificio de los animales se realizó por dislocación de las vértebras cervicales y sangrado, a través de una incisión de la vena yugular, con ayuno previo de 12-14 h (Sánchez et al., 2016).

Seguidamente, a las 4 horas post mortem, se evaluaron las propiedades tecnológicas de la carne. Todas las evaluaciones se realizaron utilizando el músculo Longissimus dorsi. El pH se midió usando un medidor de $\mathrm{pH}$ (Handylab, Alemania). La capacidad de retención de agua (CRA) se evaluó de acuerdo con los procedimientos estándar descritos por Castro y Narvaéz (2013). El color se determinó usando el sistema CIELAB: L* (índice de luminosidad), $a^{*}$ (índice de coloración amarillo/azul) y b* (índice de coloración rojo/azul) a través de un colorímetro (Konica Minolita, CR 400/410, Japón) (Pérez y González, 2003).

Una vez caracterizada la carne, se procedió al análisis de la cadena de comercialización con especial atención en los actores más importantes. Para ello se utilizó como herramienta un paquete de guías de entrevistas dirigidas a cada uno de los actores de la cadena de distribución. Los entrevistados fueron definidos con base en conocimientos previos del mercado y a estudios relacionados con el tema: lista preliminar añadiendo contactos.

RESULTADOS

Según los resultados obtenidos, de la entrevista realizada, en la actualidad, a los únicos sitios hacia donde se exportan carne de cuy es EE.UU. y España, donde se encuentran los potenciales demandantes de este producto que son los emigrantes ecuatorianos. De igual manera, países como Japón están interesados en comprar cuyes ecuatorianos. En específico, para EE.UU. se determinó que la forma de comercialización para los cuyes es la del mercado tradicional que lo realiza el mayor número de productores mediante la venta de cuy gordo "en pie" y "al ojo", pie de cría y hembras de descarte.

Respecto al cuy gordo, en pie y al ojo, en el proceso de comercialización no hay control de calidad, por el desconocimiento de los productores muchas veces no se toman en cuenta si se trata de hembras preñadas, hembras jóvenes, descartes y otros aspectos. En relación al pie de cría, se maneja con mejor tecnología, se ofrecen animales hembras seleccionados para pie de cría, que generalmente son animales de mejores características genéticas, las mismas que se venden cuando alcanzan pesos entre 700 a 800 gramos en promedio.

Cabe destacar que, productores con conocimientos técnicos no tienen problemas en el mercado, eso se debe a que al producir animales con calidad en el engorde y en la presentación, se venden en cualquier época, recibiendo mejores precios por el producto, en este caso el peso de los animales es de 1200 a 1400 gramos. 
Al referirse a las hembras de descarte, este tipo de rubro reviste mucha importancia para los productores, en razón de que los compradores mayoristas de asaderos son los que pagan mejores precios, estos animales tienen un peso que oscila entre 1400 a 2200 gramos. Una vez seleccionados los cuyes de 800 a 1200 gramos, con 10 semanas de edad, deben ser criados técnicamente, con un control en las etapas de crecimiento, engorde, sin enfermedades, como tampoco la presencia de parásitos, los cuyes seleccionados deben ser una excelente calidad. La figura 3 muestra el proceso de faenamiento.



Figura 3. Proceso de faenamiento

Como consecuencia de las principales exigencias para el consumo y conservación de la carne, se requiere la eliminación de cuanta sangre sea posible, no solo porque su presencia da un aspecto desagradable, sino porque además este es un excelente medio para el crecimiento de microorganismos.

Luego con la finalidad de incrementar la comercialización, ofertar una nueva presentación del producto y llegar al mercado norteamericano, se propone el cuy faenado empacado al vacío (Figura 4). Esta nueva presentación del producto permitirá abrir un nuevo abanico de oportunidades para ofertar cuyes pelados, ya sean enteros o en cortes a nivel interno y externo, y esto a su vez permitirá incrementar la producción de los pequeños y grandes productores. 


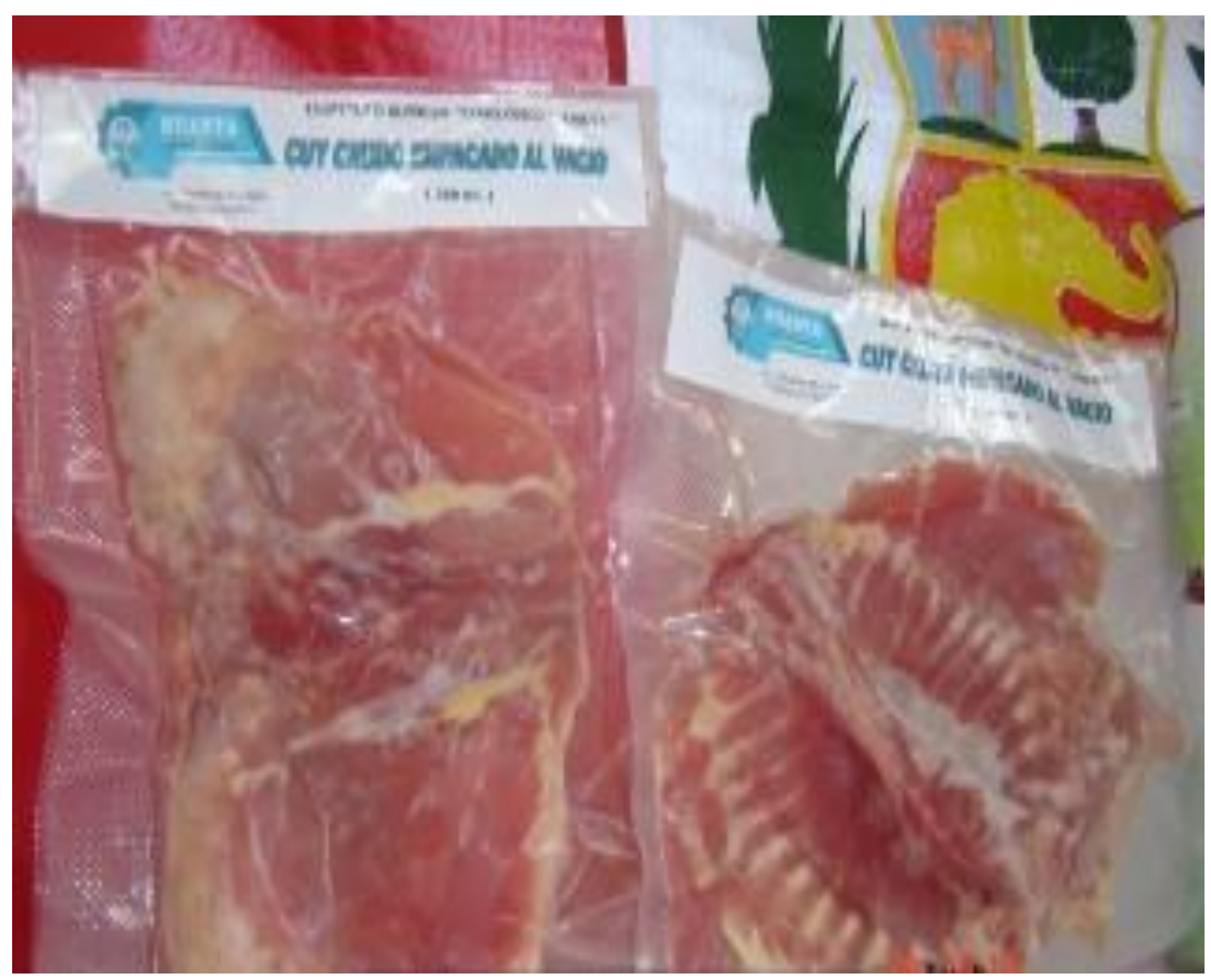

Figura 4. Cuy faenado empacado al vacío, Fuente: ECUANUTRIONIMEX S.A (2021).

Este proceso consiste en empaquetar y refrigerar el cuy faenado, la forma más simple de envasado en atmósfera modificada, consiste en eliminar el aire del sistema y mantener la carne en un envase al vacío. El envasado al vacío es el método más frecuente utilizado para el almacenamiento y distribución de la carne refrigerada para su venta al por mayor. Se escoge este tipo de presentación del producto por su excelente presentación para la exportación y su larga durabilidad en su conservación, esto permite cumplir con los estándares de calidad y con los gustos y preferencias de los consumidores finales. La figura 5 muestra el flujograma del proceso de faenamiento. 


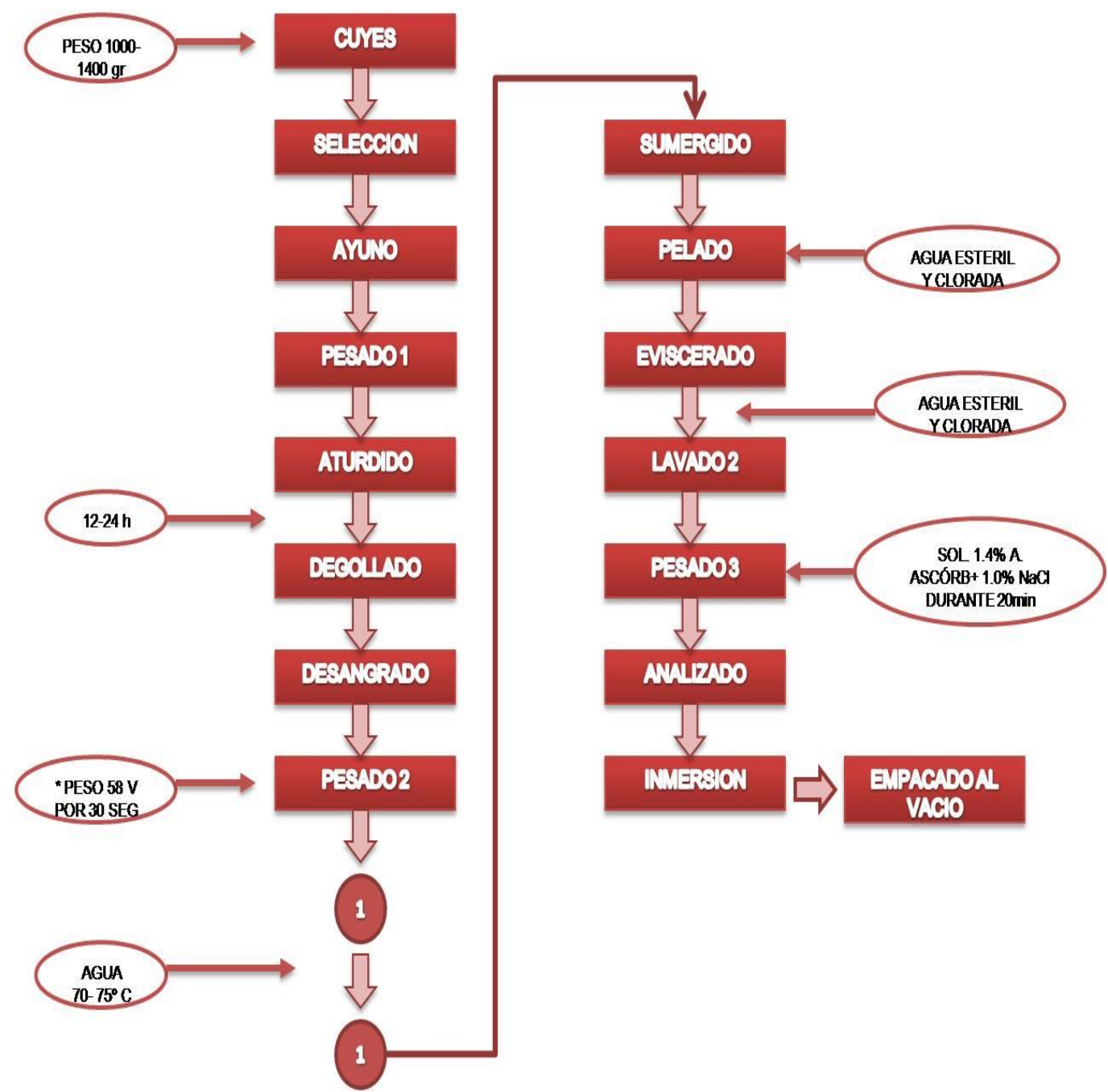

Figura 5. Flujograma del proceso de faenamiento.

Una vez obtenido el producto, el sistema de negociación se realizará a través de un intermediario directo, representado por la Exportadora Ecuafood de Nueva York EE.UU. Esta empresa actualmente se dedica a la exportación de carne de cuy desde Ecuador y al mes moviliza 6.000 unidades. La selección de esta empresa se debe a que la misma se encuentra posicionada y tiene sus principales puntos de distribución que son: Supermercados y Restaurantes Latinos donde el consumidor final lo adquirirá como "Cuy asado parrillero".

Por otro lado, es importante acotar que la carne de cuy, al igual que cualquier otro producto que se comercializa internacionalmente, está sujeta a restricciones arancelarias y paraarancelarias. No obstante, atendiendo a que Ecuador es un país subdesarrollado y al esfuerzo que se hace en materia de lucha contra el narcotráfico, la carne de cuy goza de una serie de beneficios. Así, para el caso del mercado norteamericano, la carne de cuy por pertenecer al sector agrícola está incluida dentro de la lista de productos del Acuerdo de Preferencias Arancelarias Andinas "ATPDEA". 
De igual manera, y según las regulaciones del Food \& Drug Administration (FDA), este producto deberá cumplir con regulaciones de etiquetado que establece este organismo, así como la certificación de haber sido procesado bajo los estándares sanitarios demarcados por la FDA. Este organismo regula la seguridad, sanidad y etiquetado de los productos, vigilando que se cumpla con las leyes que administra, incluyentes de la Ley Federal sobre los Productos Alimenticios, Farmacéuticos y Cosméticos (FFD \& CAct) y la Ley para la Precisión de las Etiquetas y el Empaque Adecuado (FPLA). Además, es importante contar con la certificación ISO 9000 para satisfacer la exigencia del comprador o para lograr una ventaja competitiva.

\section{DISCUSIÓN}

La idea de negocio "Exportación de cuy empacado al vacío al mercado de Nueva York, Estados Unidos" se basa en satisfacer la demanda de productos con alto valor nutritivo, tradicionales de Ecuador y exóticos con un envase práctico y listo para su uso y preparación. En tal sentido, se busca resaltar las bondades que presenta la carne de cuy presentando un producto fresco, cómodo y listo para su preparación.

A este respecto, se constató que la carne de cuy es magra; con un contenido de grasa menor al $10 \%$, alto contenido de proteínas y bajo en colesterol y sodio es ideal para incluirla en una alimentación variada y equilibrada apta para todos los grupos poblacionales, desde niños hasta ancianos, y en diversas situaciones fisiológicas, como, por ejemplo, el embarazo o la lactancia.

La carne es suave, con alta calidad nutritiva y de fácil digestión (Chávez, 2013); además, presenta una serie de beneficios para la salud humana, ya que es fuente de proteína, hierro y vitamina B12, razón que la posiciona como un excelente alimento dietético (Argote y Cuervo, 2012). Así pues, cabe resaltar que, el cuy como producto alimenticio nativo, de alto valor proteico, es bajo en grasas, contiene alta presencia de sustancias esenciales para el ser humano como el ácido graso araquidónico (AA) y el ácido graso docosahexaenoico (DHA).

Dichas sustancias no se encuentran en otras carnes, estas sustancias son importantes para el desarrollo de neuronas, membranas celulares (protección contra agentes externos) y forman el cuerpo de los espermatozoides, asimismo cuenta con minerales, vitaminas y conserva un alto aporte en hierro (cuyo proceso de desarrollo está directamente ligado a la dieta alimentaría de los sectores sociales de menores ingresos del país), en comparación con otras carnes, por lo que podría combatir la anemia y la desnutrición en gestantes y recién nacidos, tal como se menciona en el documento Perfil Comercial Cuy, del Organismo Público Sierra Exportadora (2013).

Estas características de la carne del cuy, otorgan bondades para consolidar su exportación utilizando el empacado al vacío, el cual representa un sistema importante de mantenimiento de la calidad natural de los productos cárnicos. Con una barrera apropiada contra el oxígeno, excluye el aire y el oxígeno del envase, inhibiendo consecuentemente el crecimiento de algunos organismos alterantes y extendiendo la vida útil del producto (Barros, 2004).

Ahora bien, a nivel internacional, Estados Unidos representa un mercado factible, dado el número de ciudadanos ecuatorianos que viven en este país. El 


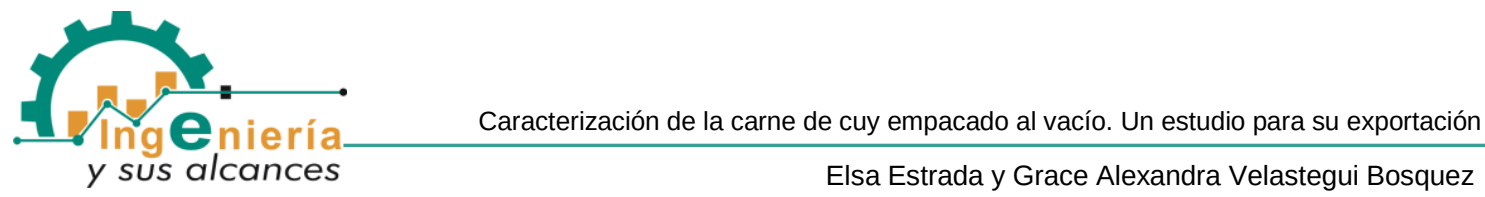

análisis del mercado realizado determinó que existe una costumbre de consumo de animales con peso de más de $800 \mathrm{~g}$ de carcasa, lo cual constituye una particularidad a ser considerada para su atención.

Estos pesos de carcasas superiores a $800 \mathrm{~g}$ se logran con cuyes que pesan más de $1000 \mathrm{~g}$ en peso vivo, por lo que se tendrá que optar por alternativas tecnológicas en los sistemas de crianza que permitan lograr estos pesos (en machos pasados los 2,5 meses surgen peleas que pueden dañar las carcasas). Esta exigencia de peso representa un inconveniente para el criador por lo tanto es necesario considerar jaulas o pozas individuales. Otra alternativa es la crianza de solo hembras hasta más de los 3 meses en que se alcanzan los pesos requeridos por este mercado.

\section{CONCLUSIONES}

La explotación de cuyes en el Ecuador es una actividad que ha venido en alza desde hace muchos años atrás mediante la inclusión de nuevas líneas mejoradas y la tecnificación de explotación, ya sea por iniciativa de los mismos interesados como con la intervención de muchas instituciones públicas y privadas.

Mediante la caracterización de los cuyes autóctonos de los Andes, se logra optimizar los diferentes sistemas de producción existentes con cuyes de mejor calidad cárnica, aprovechando su rusticidad y resistencia a enfermedades, características invalorables de los animales autóctonos.

El cuy posee un potencial cualitativo y productivo que puede transformarse en un agronegocio rentable en algunas zonas de la sierra ecuatoriana y de las zonas andinas ecuatorianas, este es el caso del cuy de restringida difusión y crianza, pero que cuenta con un importante conjunto de alternativas de producción y comercialización a nivel nacional e internacional.

EE.UU. es el principal mercado de la carne de cuy y también uno de los más exigentes, en lo que a calidad de producto se refiere. La Food and Drugs Administration (FDA) es la máxima entidad norteamericana que norma y vigila la salubridad de los alimentos importados a ese país. Si bien es cierto, la FDA no exige un certificado sanitario específico para la importación de alimentos, los importadores deben contar con los documentos necesarios que demuestren la inocuidad de estos.

Se determinó que la exportación del cuy es un negocio que ha logrado causar gran expectación en EE.UU. debido a que la carne de cuy se caracteriza por presentar buenas características nutritivas, como 19,1\% de proteína y 7,41 \% de grasa.

\section{REFERENCIAS}

Apráez, J., Fernández, L. y Hernández, A. (2011). Evaluación de diferentes formas de presentación de la carne de cuy (Cavia porcellus). Veterinaria $y$ Zootecnia, 5(2), 24-29. Disponible en: $\mathrm{http} / / /$ vetzootec.ucaldas.edu.co/downl oads/v5n2a02.pdf

Argote, F, y Cuervo, R. (2012). Agroindustrialización de la carne de cuy. Revista Guillermo de Ockham, 10(2): 217-218

Barros, J. (2004). Efecto de una técnica avanzada de envasado. Alimentación, equipos y tecnología 1, 67-71

Bidner, B., Ellis, M., Brewer, M., Campion, D., Wilson, E. y McKeith, F. (2004). Effect of ultimate $\mathrm{pH}$ on the quality characteristics of pork. Journal of Muscle Foods, 15(2), 139-154. Doi: 10.1111/j.1745-4573.2004.tb00717.x 
Castro, K. y Narváez, W. (2013). Calidad sensorial y pérdidas por cocción en carne de cerdo: efecto del sexo y fuente de selenio. Biotecnología en el Sector Agropecuario y Agroindustrial, 11(1), 130-135

Chauca, L. (2016). Impactos y retos en la investigación en cuyes para su desarrollo y consolidación empresarial. En: Simposio Nacional «Avances y Perspectivas en la Producción de cuyes». Lima. Perú: UNALM

Chávez, S. (2013). Tecnologías de Producción y Comercialización de carne de cuy procesada para el mercado nacional y de exportación. Editorial GOYOQ. Lima, Perú

Cruz, H. (2008). Manejo Técnico de Cuyes. Primera Edición, Ambato, Ecuador, Págs.7 - 60

Manual Agropecuario (2002). Biblioteca del Campo, Producción de Cuyes. Ambato

Meza, G., Cabrera, R., Morán, J., Meza, F., Cabrera, C.A., Meza, J., y Dicado, J. (2014). Mejora de engorde de cuyes (Cavia porcellus L.) a base de gramíneas y forrajeras arbustivas tropicales en la zona de Quevedo, Ecuador. IDESIA, $32(3), \quad 75-80$. doi: 10.4067/S07183429201400030001

Ministerio de Agricultura, Ganadería, Acuacultura y Pesca (MAGAP, 2019). Crianza de cuyes ayuda a reconversión de actividades productivas. Disponible en:

https://www.agricultura.gob.ec/crianz a-de-cuyes-ayuda-a-reconversion-deactividades-productivas/

NC ISO: 1035. (2021). Análisis sensorial. Identificación y selección de descriptores para el establecimiento de un perfil sensorial mediante un enfoque multidimensional. Oficina Nacional de Normalización de Cuba

Pérez, S. y González, M. (2003). Application of absorbance values used in wineries for estimating CIELAB parameters in red wines. Food Chemistry, 81(2), 301-
$306 . \quad$ doi: $10.1016 / \mathrm{S} 0308-$ 8146(02)00509- 5

Perfil comercial del cuy, documento Perfil Comercial Cuy, del Organismo Público Sierra Exportadora (2013). Disponible en:

http://www.sierraexportadora.gob.pe/ perfil_comercial/cuy

Robles, K., Pinedo, R., Morales, S. y Chávez, A. (2014). Parasitosis externa en cuyes (Cavia porcellus) de crianza familiarcomercial en las épocas de lluvia y seca en Oxapampa, Perú. Rev Inv Vet Perú, 25(1), 51-57. Doi: 10.15381/rivep.v25i1.846

Sánchez, J., Hernández, D. y Durán, D. (2010). Valoración del forraje verde hidropónico de maíz (FVH) sobre la calidad de la canal del conejo raza Nueva Zelanda. Alimentech Ciencia y Tecnología Alimentaria, 8(1), 5-15. Doi: 10.24054/16927125.v1.n1.2010.442

Sánchez, D., Castro, N., Rivero, M.A., Argüello, A. y Morales, A. (2016). Proposal for standard methods and procedure for guinea pig carcass evaluation, jointing and tissue separation. Journal of Applied Animal Research, 44(1), 65-70. doi: 10.1080/09712119.2015.1006234

Tandzong, C., Mbougueng, P., Womeni, H. y Ngouopo, N. (2015). Effect of cassava leaf (Manihot esculenta) level in guineapigs (Cavia porcellus) meal on the physico-chemical and technological properties of its meat. Food and Nutrition Sciences, 6(15), 1408-1421. doi: 10.4236/fns.2015.615146

Zaldívar, A.M. (2001). Estudio de la edad del empadre de cuyes hembras (Cavia porcellus) y su efecto sobre el tamaño y el peso de camada. La Molina, Lima, Perú. 119 Págs

Zhang, S., Farouk, M., Young, O., Wieliczko, K. y Podmore, C. (2005). Functional stability of frozen normal and high $\mathrm{pH}$ beef. Meat Science, 69(4), 765-772. doi: 10.1016/j.meatsci.2004.11.009 